\title{
The causes and management of impotence
}

\author{
Alan J. CoOper \\ M.D., M.R.C.Psych., D.P.M. \\ Director of Clinical Research, Huntingdon Research Centre, Huntingdon

\section{Hon. Consultant Psychiatrist, Peterborough District Hospital}

IMPOTENCE may be defined as the inability of the male to develop and/or sustain an erection of the penis sufficient to conclude coitus or orgasm and ejaculation to his own satisfaction. The condition may be 'primary', i.e. early onset-present since the first attempt at coitus, or 'secondary', i.e. late onset-developing from prior competency. The causes of impotence may be arbitrarily divided into three main groups: 'constitutional', 'organic' and 'psychogenic'. 'Extreme' constitutional impotence is likely to be associated with persisting evidence of low sexual drive and responsiveness; rarely, there will be no prior history of, or as is more usual, only spasmodic episodes of self-masturbation; and other types of sexual outlets, such as heterosexual petting/ coitus and/or homosexuality, will have taken place only very infrequently or not at all. As far as can be established there is no organic pathology in these cases, who seem merely to occupy one pole of a 'sexual responsiveness' continuum, at the other end of which is situated the high responder, i.e. $>$ thirty outlets/week-Kinsey, Pomeroy \& Martin (1948). Unless constitutional factors are dominant, 'organic' impotence will usually have developed from prior competency in association with some pathological lesion. The condition is generally held to be constant and persists largely unchanged, irrespective of the nature of any sexual stimulation which might be provided. On the other hand 'psychogenic impotence' is stated to be selective and transient, occurring in certain situations and at certain times, but not others. In clinical practice, impotence is rarely seen in 'aetiologic pure culture', indeed, in the majority of cases aetiologic overlap may occur and it is important to realize that although a case may be predominantly 'organic'; 'psychogenic' and/or 'constitutional' factors may and usually are playing a part to some degree or other. Likewise with predominantly 'psychogenic' and predominantly 'constitutional' types.

This paper is aimed mainly at the non-psychiatrist; its purpose is to summarize the main causes of impotence and to describe a practical management approach, which does not require much in the way of psychological expertise for its use. It is hoped thereby that many otherwise reluctant practitioners may be encouraged to try out their 'hand'.

\section{Organic impotence}

This probably accounts for less than $5 \%$ of cases and may occur with any debilitating disease, with metabolic disorders, with disorders of the central nervous system, cardiovascular diseases and endocrinopathies, as well as following the use of some drugs. Table 1 , which is a slightly larger version of Masters' \& Johnson's (1970) culling from the literature, shows the range of organic pathology which has been held to cause impotence. Since in many cases this is derived from a few or even single case studies, these 'causes' should be viewed, at best, only as probabilities.

\section{Psychogenic impotence}

Most authorities agree that in the overwhelming majorityof cases, psychological factors are dominant The more important may be briefly summarized 8 under the following headings.

\section{(1) Anxiety and fear}

Many diverse fears and anxieties are apparently capable of causing impotence. These include: fear of disease, fear of pregnancy, fear of inflicting injury on the partner and fear that the partner will resent being deprived of her virginity. Anxieties of one form or another may become superimposed upon an organic condition, such as diabetes, etc., and exacerbate and/or perpetuate the sexual dysfunction. It is for this very reason that in a percentage of cases, even when the organic illness has been reversed or compensated for, the impotence persists.

\section{(2) Hostility and resentment}

According to many psycho-analysts and behaviourists alike, hostility is often found in association with impotence. Stekel (1927), for instance, noted that impotence sometimes corresponded with a desire to punish the spouse. Certainly, in clinical practice it is not particularly unusual to find a 'revenge motive' in association with erectile insufficiency. Gutheil (1959) has referred to this as the 'war between the sexes'.

\section{(3) Disgust}

Disgust related to the female genitalia (and in particular vaginal mucus), which are often misconstrued as having excretory functions, may underlie impotence in some cases. 
TABle 1. Organic causes of impotence

\begin{tabular}{|c|}
\hline $\begin{array}{l}\text { Anatomical } \\
\text { Congenital deformities } \\
\text { Testicular fibrosis } \\
\text { Hydrocele }\end{array}$ \\
\hline $\begin{array}{l}\text { Cardiorespiratory } \\
\text { Angina pectoris } \\
\text { Myocardial infarction } \\
\text { Emphysema } \\
\text { Rheumatic fever } \\
\text { Coronary insufficiency } \\
\text { Pulmonary insufficiency }\end{array}$ \\
\hline $\begin{array}{l}\text { Drug ingestion } \\
\text { Addictive drugs } \\
\text { Alcohol } \\
\text { Alpha-methyldopa } \\
\text { Amphetamines } \\
\text { Atropine } \\
\text { Chlordiazepoxide } \\
\text { Chlorprothixene } \\
\text { Guanethidine } \\
\text { Imipramine } \\
\text { Methantheline bromide } \\
\text { Monoamine oxidase inhibitors } \\
\text { Phenothiazines } \\
\text { Reserpine } \\
\text { Thioridazine } \\
\text { Nicotine (rare) } \\
\text { Digitalis (rare) } \\
\text { Pesticides (rare) }\end{array}$ \\
\hline $\begin{array}{l}\text { Endocrine } \\
\text { Acromegaly } \\
\text { Addison's disease } \\
\text { Adrenal neoplasms (with or without Cushing's syndrome) } \\
\text { Castration } \\
\text { Chromophobe adenoma } \\
\text { Craniopharyngioma } \\
\text { Diabetes mellitus } \\
\text { Eunuchoidism (including Klinefelter's syndrome) } \\
\text { Feminizing interstitial-cell testicular tumors } \\
\text { Infantilism }\end{array}$ \\
\hline
\end{tabular}

Anatomical

Hydrocele

Angina pectoris

Myocardial infarction

Coronary insufficiency

Pulmonary insufficiency

Addictive drugs

Alcohol

Atropine

Chlordiazepoxide

me bromide

Phenothiazines

Nicotine (rare)

Digitalis (rare)

Acromegaly

Castration

Chromophobe adenoma

Craniopharyngioma

Feminizing interstitial-cell testicular tumors

Infantilism
Ingestion of female hormones (oestrogen)

Anti-androgens

Myxedema

Obesity

Thyrotoxicosis

Genitourinary

Perineal prostatectomy (frequently)

Prostatitis

Phimosis

Priapism

Suprapubic and transurethral prostatectomy (occasionally)

Urethritis

Haematological

Hodgkin's disease

Leukaemia, acute and chronic

Primary anaemia

Infectious

Genital tuberculosis

Gonorrhoea

Mumps

Neurological

Amyotrophic lateral sclerosis

Cord tumours or transection

ECT

Multiple sclerosis

Nutritional deficiencies

Parkinsonism

Peripheral neuropathies

Spina bifida

Sympathectomy

Tabes dorsalis

Temporal lobe lesions

Vascular

Aneurysm

Arteritis

Sclerosis

Thrombotic obstruction of aortic bifurcation

Haemorroids
(4) Inversion of the sex drive

Sexual deviations of one sort or another including homosexuality, fetishism, transvestism, sadism, masochism, and excessive autosexuality (self-masturbation) may be associated with sexual aversion manifesting as heterosexual impotence.

\section{(5) Inhibition}

Sexual inhibition may be defined as self-imposed restraint from engaging in any type of sexual practice or experimentation which an individual feels desirous of, and which he thinks would be satisfying. A concomitant is that in his sexual fantasies he engages in and enjoys vicariously those sexual activities which in real life he is too inhibited to perform. Characteristically, the inhibited male is usually unable to communicate his sexual desires to his partner, most often fearing rebuff or accusations that he is perverted. Inhibition is due largely to culturally imbued taboos impressed at school and/or home. According to Masters \& Johnson (1971), the single most important influence in inhibition is excessive religious orthodoxy, which, for instance, condemns (a) masturbation as being 'sinful and unnatural', (b) pre-marital petting as wicked, and (c) nocturnal emissions as being 'pollutions', etc. The position is poetically summed up by Walker \& Strauss who quote thus: 'there is a disposition on the part of some married couples to feel that while certain methods of lovemaking are right and proper, others are illegitimate and degrading. It is chiefly because the British pay great respect to medicine that their method of lovemaking rarely departs from a certain accepted model. But love has not always been so 
conventional. In the Khama Sutra we read of at least seven different ways of kissing; eight varieties of touch, eight playful bites, four methods of stroking the body with the hands and eight sounds which may be emitted whilst doing so. For the India of Khama Sutra, sexual congress was looked upon not merely as a conjugal duty, or as the necessary preliminary to the obtaining of children, but as an activity from which both partners could derive pleasure and experience among the richest which life could provide them and in writing his great work on love the author was in no way pandering to the sensuousness of youth. On the contrary, there is every reason to believe that when he penned it he was, himself, living the life of a religious recluse in Benares. In undertaking this work at such a time, he must, of necessity, have felt that in sexual love there was no element that need be in enmity with or in any way contradict the highest spiritual aspirations of mankind'.

\section{(6) Personality factors}

Impotence may be a presenting symptom of a deep-seated personality disorder or neurotic conflict; this is especially true of psychopaths and other markedly egocentric people, in whom the impotence may be symptomatic of an inability in general to engage in affectionate relationships with other people. It is perhaps worthwhile pointing out that some of the most bizarre types of sexual inadequacy may be found in association with severe personality immaturity. For example, the rare condition orgastic impotence (ejaculation without orgasm) may be found in men who, quite simply, do not have the capacity to love (Gutheil, 1959). Impotence in association with severe personality disorder is extremely difficult to treat, and should be left for the psychiatrist.

\section{(7) Ignorance and mis-information}

Among the commoner myths found in association with impotence are the following: (a) ignorance of the normal biological variation in sexual prowessmany men who fail to live up to a popular sexual stereotype (usually a sexual superman) become discouraged and ultimately fail sexually, (b) beliefs that a 'drop of semen equals a pint of blood' and that excessive masturbation may be damaging, both to the sexual organs and/or the brain, and (c) sexual proficiency is directly proportional to the size of the penis-big ones being more effective than small ones, etc.

\section{(8) Impotence and ageing}

Although the underlying mechanisms are not fully understood there is no doubting the inverse relationship between ageing and potency. Kinsey believes that, in the main, this is 'psychological' in origin, being due to constant repetition over many years, with the same partner, of the same sort of activity. Whilst this is predictably true for older males, it seems that it may also hold for a minority of much younger, low drive, ones (30-40) (Cooper, 1967), who rapidly habituate within a few years of marriage and become incapable of responding to stimulations which formerly were exciting.

\section{(9) Functional psychoses}

Impotence may be symptomatic of endogenous and less frequently reactive depression. It has also been reported in association with schizophrenia and paranoia.

This summary of the main psychological causes of impotence is by no means complete or exhaustive. Its main function is to draw attention to the diverse psychopathology that might operate in the individual case; to provide an aetiological check list, as it were, which the physician can tick off during history taking, in arriving at his diagnostic formulation.

\section{History-taking and investigations}

A detailed psychosexual history is essential from both sexual partners. Ideally, if time permits, this should be taken first individually, then together. All aspects of sexual development and experience should be covered. Topics are best dealt with chronologically, somewhat as follows:

(1) first awareness of sex and sexuality;

(2) puberty data, e.g. the time of initial ejaculation, time of development of secondary sexual characteristics, attitudes to this, etc.;

(3) masturbation history, including frequencies, attitudes, fantasies, methods of stimulation, pattern throughout adolescence and up till present, etc.;

(4) types and extent of pre-marital sexual experiences, including homosexual and heterosexual, etc.;

(5) summary of sexual experiences and activities up to the initial failure;

(6) circumstances, and type of initial failure, e.g. pre-maturity, impotence, delayed or absent ejaculation, others; any other symptoms, etc.;

(7) subsequent sexual history up to the time of consultation including the type and frequency of any alternative sexual outlets, such as masturbation, etc.;

(8) current relationship between the sexual partners.

After the history has been taken a physical examination of the genitalia should be carried out. If there is clinical evidence, other than the impotence, pointing to an organic cause (see Table 1) appropriate clinical and/or laboratory investigations should be carried out. Even if it turns out that the immediate provoking cause may be organic; impotence whatever its antecedents invariably induces marked feelings of sexual inferiority, fear or anxiety, 
etc., which may exacerbate and/or perpetuate the dysfunction. The psychosexual components of the history, therefore, aim to define possible 'remedial' psychological contributory causes, which may overlap and complicate any organic leison. It cannot be stressed forcibly enough that a detailed history from both parties is a necessary precurser to optimum therapy.

\section{Treatment}

In the infrequent cases in which an organic disorder is confirmed, treatment consists of specific remedial measures, i.e. temporal lobectomy for a tumour-Johnson (1965), drug and dietary control of diabetes (Cooper, 1972) etc., aimed to restore maximum physical wellbeing, together with 'psychophysiologic therapy' as described below for 'psychogenic impotence'. The most important components of psychophysiologic treatment are the provision of (1) 'optimum sexual stimulation', (2) sexual education and (3) superficial psychotherapy.

\section{(1) Optimum sexual stimulation}

This is the combination of psychological and physical stimuli which allow a male to respond to his sexual capacity. It can only be provided if the male is in an emotionally receptive state of mind and wishes to respond, and the female sexual partner is willing and able to co-operate fully in providing the type and intensity of stimulation required. Many males who emotionally desire it are unable to engage in certain types of sexual practices or experimentations because of a fear that they might be rebuffed as perverted; they are often concomitantly unable to discuss these matters with their partners. An important part of therapy is to promote frank communication between the sexual partners and to help them to gain insight into each other's sexual attitudes, preferences, inhibitions, etc. It is hoped that this might encourage the couple to experiment sexually and to improve mutually the variety and intensity of their stimulative caresses.

However, insight - that is, intellectual awareness that one is not sexually depraved and that one's fantasies and unfulfilled sexual desires may, in fact, be enjoyed by numerous other perfectly normal individuals-may make it no easier to throw off restraint, developed and consolidated over many years. In its actual implementation a slow progressiveness, but always within the limits of emotional tolerance, is advised. For example, an inhibited couple should be advised to communicate verbally to each other their stimulative requirements, degree of arousal, satiation, etc., and to experiment in such fashion as to become a little less inhibited and more adventuresome each time; always providing that this is compatible with 'emotional comfort'.

An important pre-requisite is that they should only engage in new practices when both are fully roused. In order to re-inforce each new 'unrestrained pattern of sexual stimulation' it is important that a degree of satisfaction results each time. Therefore, if a situation arises when any type of sexual experimentation evokes anxiety or alarm, a couple should discontinue this and revert to a familiar and predictably pleasurable activity. The objective is to arrive at the point by mutually acceptable experimentation where each partner has discovered means of producing maximum arousal in the other without anxiety or shame. Although in the first instance the female is advised to take a greater initiative in sexual activity, it is incumbent upon the male to respond reciprocally as his confidence grows. Ultimately, he is likely to assume the dominant role. The impotent male is told to avoid coitus until he is able to develop and maintain erections for several minutes. Thus, he knows that he is under no obligation to succeed and, perhaps, for the first time in many months he is able to relax and concentrate on enjoying sensual stimulation as a means of rousing him.

Both partners are encouraged to linger over noncoital sex play in order to maximize the possibility of full arousal. This is not a time-limited exercise; indeed, it should take the form of a leisurely comfortable stimulative exchange without obligation on either side. At this point the object is to concentrate on enjoying bodily sensations; nothing more and nothing less. Initially this takes the form of mutual bodily stroking of the non-genital areas; the arms, thighs, small of the back, etc. As sexual tension develops and increases the female is encouraged to handle the male's penis as directed by him, sufficiently to induce and maintain a good erection. This is repeated over several sessions and it is only when an erection can predictably be maintained that coitus is considered. In the impotent male, for a variety of anatomical and psychological reasons the best position for coitus is the dorsal, with his partner sitting astride him. When coitus is attempted, she once more should take the initiative. She should guide the male's penis with her hand into the vagina. Thus, the male retains his 'non-obligation status' and is able to concentrate exclusively on the sensual pleasure of intravaginal containment. Gentle pelvic thrusting may be added once the male is confident of retaining his erection intravaginally.

Therapeutic sessions should be practised at least twice a week, whether or not spontaneous sexual desire is present. Even when confidence has been restored the extensive foreplay described above is mandatory. The male is advised never to attempt penetration unless he is firmly erect and sexually desirous. 


\section{(2) Sexual education}

As indicated sex information should be given to both partners, jointly, who should be encouraged to ask any questions they might have. For instance, it may often be necessary to: (a) provide information on coital techniques, female sex anatomy, physiology and psychology, and (b) rectify false impressions, the consequence of mis-information obtained during adolescence. Thus, a not uncommon problem is the notion that certain sexual practices are, innately, abnormal or perverted, and therefore, strictly taboo. It should be stressed to both that any variety of stimulation or caress which is mutually pleasurable and emotionally acceptable is perfectly 'normal' and can be indulged without fear or guilt.

\section{(3) Psychotherapy}

In essence this consists of superficial counselling concerned with creating and maintaining, as far as possible, the conditions in which the practical components of treatment can be carried through optimally. Emphasis is on explanation, education and encouragement. Psychological interpretations are kept to a minimum and transference situations which are unnecessary are not encouraged.

\section{Limitations of treatment}

The therapy described, which may be applied by any 'non-inhibited' practitioner with an empathic interest in the subject, is suitable for the majority of cases of impotence and should be applied for up to 6 months. This period has been seen empirically to be about optimal; thereafter, if improvement is not seen, motivation wanes and further deterioration of the condition is likely. Patients who show significant psychological disturbance, particularly personality disorder, should be referred immediately for psychiatric assessment. In these cases the impotence may be one facet of this wider disturbance and is unlikely to change unless the personality does. Personality disorder is difficult to treat whatever method is used.

\section{Prognosis}

With the above practically orientated treatment, approximately $40-50 \%$ of 'across the board' cases may be expected to improve. Factors associated with a better treatment outcome are:

(a) acute onset impotence of short duration;

(b) a heterosexual sex drive;

(c) presence of 'sex desire' in the coital situation;

(d) a sympathetic spouse willing to participate fully in the programme.
If there is no improvement in the impotence after 6 months of technically satisfactory treatment (fort- $c$ nightly sessions) then further practical measures, $\overrightarrow{\vec{F}}$ however prolonged, are likely to be useless. At this $\stackrel{?}{\rightarrow}$ point, brief supportive psychotherapy aimed to help the sufferer and/or his partner accept his incompetency is indicated. In summary the main objectives of this are:

(a) to encourage, as far as is emotionally acceptable of to both, non-coital stimulations (most often mutual masturbation and other bodily caresses) to reduce sexual tension and to provide a measure of satisfaction. This may be especially important for the female, and

(b) to reassure the female that her husband's disability is in no way caused by her and see to $\vec{\infty}$ support and bolster the male's ego during the readjustment period.

\section{Prophylaxis}

It is generally agreed by most experienced practitioners that 'psychogenic' impotence is most often $\mathcal{D}^{\text {D }}$ due to inhibition; consequent upon negative conditioning; religious, social, parental, etc., through- $\frac{\Phi}{3}$ out the early formative years, and adolescence 8 (Gutheil, 1959; Masters \& Johnson, 1970; Kinse et al., 1948; Walker \& Strauss, 1948).

In the future, therefore, the best insurance again $N$ sexual morbidity is likely to lie in appropriat $\bar{\sigma}$ educational programmes; instigated, planned and implemented as a co-operative venture between parents and teachers, and other 'Social Leaders'. At present, this whole question is under vigorous debate.

\section{References}

CoOPER, A.J. (1967) Unpublished M.D. Thesis, University of Bristol.

COOPER, A.J. (1972) The diagnosis and management of endocrine impotence. British Medical Journal, $2,34$.

Gutheil, E.H. (1959) Sexual dysfunctions in men. In: American Handbook of Psychiatry (Ed. by S. Arieti), Vol. 1, pp. 708-26. Basic Books, New York.

JoHnson, J. (1965) Sexual impotence and the limbic system. British Journal of Psychiatry, 111, 300.

Kinsey, A.C., Pomeroy, W.B. \& Martin, C E. (1948) D Sexual Behaviour in the Human Male. Saunders, Philadelphia.

Masters, W.H. \& Johnson, V.E. (1970) Human Sexual Inadequacy. Churchill, London.

STEKEL, W. (1927) Impotence in the Male. Liveright, New York.

Walker, K. \& Strauss, E.B. (1948) Sexual Disorders in the Male. Williams \& Wilkins, Baltimore. 